\title{
The effects of grouping visual stimuli on the cortical evoked potential ${ }^{\prime}$
}

\author{
JACKSON BEATTY ${ }^{2}$ AND WILLIAM R. UTTAL \\ THE UNIVERSITY OF MICHIGAN, Ann Arbor, Michigan
}

The effect of grouping elements of a visual stimulus on the amplitude of the bipolar occipital evoked potential is considered in two experiments. A marked and orderly relation is found. Various classes of hypotheses are advanced to account for this finding.

Although many studies have reported effects of visual stimuli on the averaged cortical evoked potential (EP), most of these papers have been concerned with the intensity (Clynes, Kohn, \& Lifshitz, 1964; Kitajima, 1967), color (Shipley, Jones, \& Fry, 1965; White \& Eason, 1966), or temporal patterning (Donchin, Wicke, \& Lindsley, 1963; Ciganek, 1964; Donchin \& Lindsley, 1965) of the vistal display. A few have examined the effects of spatial patterning on the EP. Spehlman (1965) reports that EP waveform is markedly different for patterned and unpatterned stimuli. For the latter, the major component is a surface positive wave at $80-120 \mathrm{msec}$. For patterned stimuli, the sign of this component is reversed and a large positive wave at $180-250 \mathrm{msec}$ appears. Rietveld et al (1967) found that the amplitude of both these components varies with the size of units for checkerboard patterns, reaching maximal values for checkers of about $20 \mathrm{~min}$ arc. These authors also note that the EP to striped stimuli resembles more closely the EPs to blanks than the EPs to checkerboard stimuli.

Lifshitz (1966) examined EP to focused and defocused pictorial slides and found a large surface negative wave peaking at $250-400$ msec for the focused (patterned) stimuli. Patterning also reduced the amplitude of a 75-100 msec surface negative component. Conversely, Hof et al (1962) found that the introduction of a wire, bent in the form of a human profile, in front of an eluminated surface reduced the amplitude of components occurring after $160 \mathrm{msec}$. John, Herrington, and Sutton (1967) report that the presence of a geometric form in an otherwise blank visual field alters the waveform of the EP. Further, the form of a geometric figure is reported to be a more potent determinant of wave shape than its area. MacKay and Rietveld (1968) report that the amplitude of the EP to a moving line on a CRT increases as a function of the distance moved and is augmented by the presence of a second, reference line.

The present paper examines the effect on EP of the distribution or grouping of stimuli in the visual field.

\section{EXPERIMENT 1}

\section{Method}

$S$ sat in a sound-attenuating, darkened booth, watching an oscilloscope (Tektronix $561 \mathrm{~A}$ ) display at a distance of $70 \mathrm{~cm}$. The cathode ray tube in this oscilloscope utilized an ultra-short persistence phosphor ( $\mathrm{P}-15)$ which decays in such a manner that $50 \mu \mathrm{sec}$ after electron bombardment, light output is reduced to $.1 \%$ its maximal value. The face of the display was masked, leaving a viewing area of $37 \times 45 \mathrm{~mm}$. Horizontal line stimuli could be generated at $1-\mathrm{mm}$ intervals along the vertical dimension. Four stimulus arrays, each using 18 lines, were used (see Fig. 1). In the first array, Grid 1, lines were generated at the $1 \mathrm{st}, 3 \mathrm{rd}, 5 \mathrm{th}, 7 \mathrm{th}$, etc., positions on the vertical axis. Thus in this pattern a line was placed at every other vertical position. Alternating pairs of lines $(1,2,5,6,9,10$, etc. ) comprised Grid 2. Grid 3 was composed of triplets $(1,2,3,7,8,9,13,14,15$, etc.) and Grid 4, quadruplets $(1,2,3,4,9,10,11,12,17$, etc.) of lines. Lines were plotted from top to bottom, but, since an array was completely displayed in less than $3 \mathrm{msec}$, all lines appeared to be simultaneously generated. Display intensity was approximately $2 \log$ units above threshold. Thus the stimuli consisted of four arrays, all composed of 18 identical elements, all of equal energy, differing only in the manner in which the elements are distributed across the display surface.

These stimulus patterns were generated by a small, general purpose computer (PDP-5), which also computed the averaged evoked potentials. For each block of trials 128 instances of each grid were displayed in random order. Thus at no time was $S$ able to anticipate any stimulus with an accuracy greater than .25 . This procedure eliminated the possibility that changes in S's attentive state (Chapman, 1965), posture (Nakayama, 1965) or muscle tone (Bickford et al, 1964) could systematically bias the obtained EPs. Stimulus arrays were displayed at the rate of $2 / \mathrm{sec}$. With a fixed and rapid rate of presentation, the cortical response to any stimulus is undoubtedly influenced by the after-potentials of preceding stimuli. For this reason the obtained potentials may not be thought to represent the waveform generated by a single presentation of the stimulus. Nonetheless, the existence of these afterpotentials cannot explain any differences obtained between evoked potentials, since each stimulus is not systematically preceded by any other stimulus. The evoked potential was recorded from bipolar electrodes placed in the occipital region at approximately positions 0 and $0_{1}$ by the 10-20 system (Jasper, 1958 ), about $3 \mathrm{~cm}$ above the inion on the midline and the second electrode about $3 \mathrm{~cm}$ to the left. This signal was passed through an AC-coupled amplifier train (time constant $=.3 \mathrm{sec}$ ) to the A/D converter of the PDP-5. Sampling began with the presentation of a stimulus and continued for $450 \mathrm{msec}$. Two hundred and fifty-six conversions were made during that period. The obtained average evoked potentials were punched in digital form on paper tape for subsequent display and analysis.

Four Ss, all male undergraduates, participated in the present study. Each $S$ received four blocks of 512 stimuli, each block evenly divided between the four arrays.

\section{Results}

A typical evoked potential obtained in the present experiment is shown inset in Fig. 2. A large wave, beginning at about 100 msec, is a prominent feature in the data of all Ss. Its peak-to-peak voltage was measured in each EP.

For all Ss, Grid 1 produced the largest peak-to-peak voltage, as may be seen in Fig. 2. Its amplitude is decreased as grouping is

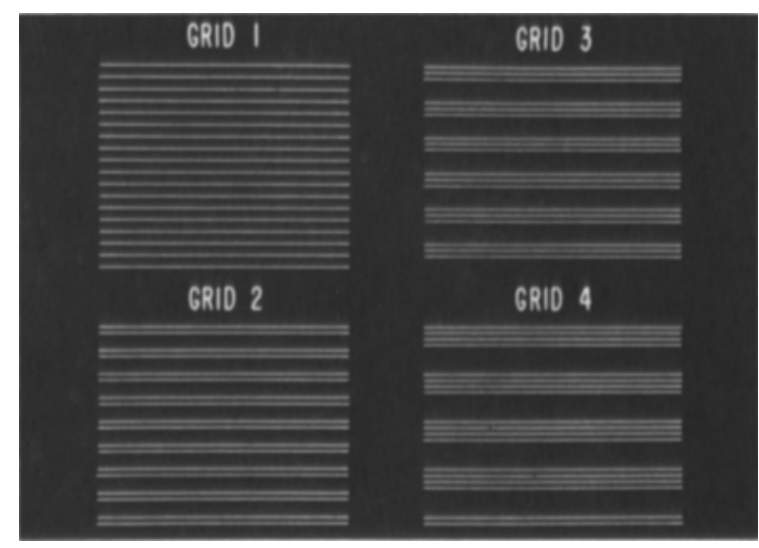

Fig. 1. Stimulus arrays used in Experiment 1. All arrays are of equal energy, differing only in distribution of the lines across the display surface. 

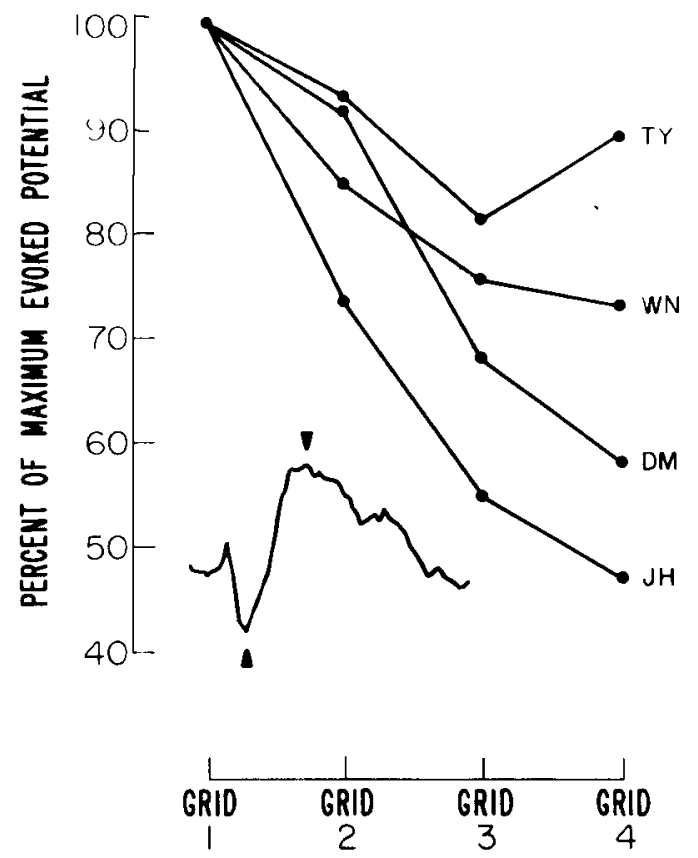

Fig. 2. The results of Experiment 1 are plotted as per cent maximum amplitude of the measured EP component for each of the four stimulus arrays shown in Fig. 1.

increased in the stimulus array. Jonckheere's rank $t$-test against ordered alternatives (1954) was used to assess the significance of this trend separately for each S. For three Ss (W. N., J. H., and D. M.) $p$ was less than .001 . For the fourth $S(T$. Y.) $p$ was approximately .0514 . Thus each $S$ showed a significant reduction in EP amplitude as a function of the grouping of line stimuli.

\section{EXPERIMENT 2}

A second experiment was undertaken to partially test the generality of the attenuating effect of grouping stimulus elements on the evoked potentials.

All procedural details in Experiment 2 were as in Experiment 1, with the exception of the stimulus arrays. In this experiment each stimulus array was composed of 36 dots. These patterns are shown in Fig. 3. In Matrix 1, the dots were evenly distributed across the display area. In Matrix 2, dots were grouped in a pairwise fashion along both $\mathrm{X}$ and $\mathrm{Y}$ dimensions. In Matrix 3, triplets were grouped on both dimensions. Adjacent dots were separated by approximately $1 \mathrm{~mm}$. They represented 2-dimensionally a grouping transform similar to that applied in Experiment 1 in a single dimension. Three Ss were run for four blocks of trials, with all three stimulus conditions represented in each block.

\section{Results}

As in Experiment 1, peak-to-peak amplitude of a major EP component beginning at about $100 \mathrm{msec}$, was computed for each obtained EP. Mean amplitude for each $\mathrm{S}$ and each stimulus array was computed. The means were then transformed to per cent of maximum EP for each $S$ and these data are plotted in Fig. 4. It may be seen that increasing grouping decreases EP amplitude for each $\mathrm{S}$.

The significance of this trend was computed separately for each $S$ using Jonkheere's (1954) rank order t-test against ordered alternatives. The calculated probability of the obtained results was in all cases less than 0.001 .

\section{DISCUSSION}

While both experiments show a strong relation between EP amplitude and the grouping of stimulus elements, neither experiment attempts to define the mechanism which mediates this effect. Moreover, the nature of the effective independent variable is not yet known. Specilically. the four-line arrays and the three-dot matrices may he ordered in the same way on several dimensions, all of whicl are completely confounded in the present studies. For example, the number of groups and the number of elements in a group covary. Similarly, the variance of the distribution of elements across the display surface is another descriptor capable of ordering the stimulus arrays. Confoundings of this nature must be systematically removed to clarify the nature of the phenomenon demonstrated in the present experiments. Isolation of the critical variables should allow a more detailed appraisal of the mechanisms responsible for the attenuation of evoked potential amplitude with the "grouping" of the elements in a visual stimulus field.

Nonetheless, two general types of mechanisms may be proposed to account for the data presented above. One is that a local process, such as a peripheral inhibitory interaction, may mediate the effect. One might argue that, within certain limits, increasing the proximity of stimulus elements decreases the amplitude of the EP to the stimulus array. Specifically in the present studies, two lines or dots displayed in adjacent locations might produce a smaller effect than if they were separated by $2 \mathrm{~mm}$ or more. Thus, the reduction of the EP with "grouping" might be seen as a function of the number of lines within the critical distance. Some preliminary data indicate that this may not be the case. Three Ss (D. M., T. Y., and J. H.) were run in a third experiment, identical to the first in all respects except the construction of the stimulus arrays. Instead of 18-line arrays, pairs of lines were presented, 1, 2, 3 , or $4 \mathrm{~mm}$ apart. It was reasoned that a local inhibitory mechanism would be indicated if the EP to the line pair at $1-\mathrm{mm}$ separation was attenuated. The obtained EPs were small, but regular in waveform. No systematic effects in amplitude could be found. Other tests of this hypothesis are currently under way.

The second class of hypotheses being considered relates EP magnitude specifically to higher order or organizational properties of the stimulus array, perhaps similar to those envisioned by the Gestalt psychologists to explain perceptual grouping. Such a factor might be the uniformity of the stimulus elements across the display surface. But before any such hypothesis can be advanced, the exact nature of the effective stimulus dimension must be known, and the effects of local processes must be excluded. This cannot be done at present.

\section{REFERENCES}

BICKFORD, R. G., JACOBSON, J. L., \& CODY, D. T. R. Nature of average evoked potentials to sound and other stimuli in man. Ann. N.Y. Acad. Sci., 1964, 112, 204-223.

CHAPMAN, R. M. Evoked responses to relevant and irrelevant visual stimuli while problem solving. Proceedings of the 73rd Annual Convention of the American Psychological Association, 1965, 177-178.

CIGANEK, L. Excitability cycle of the visual cortex in man. Ann. N.Y. Acad. Sci., 1964, 112, 241-253.

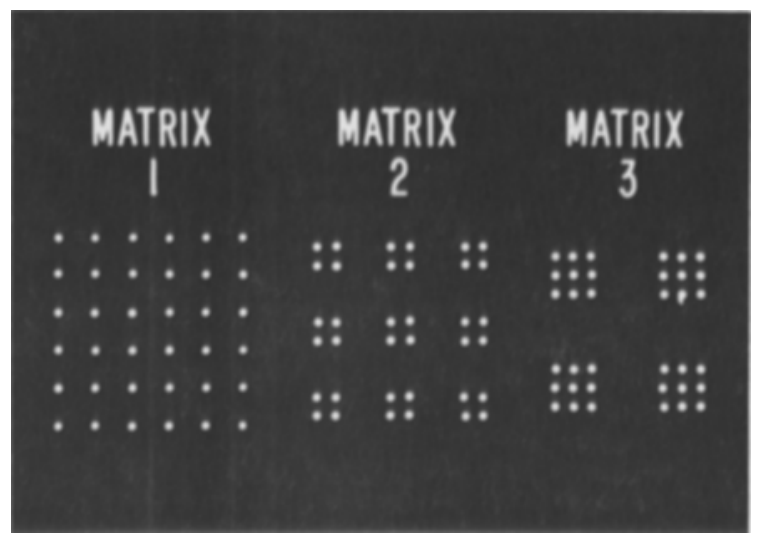

Fig. 3. Stimulus matrices used in Experiment 2. 


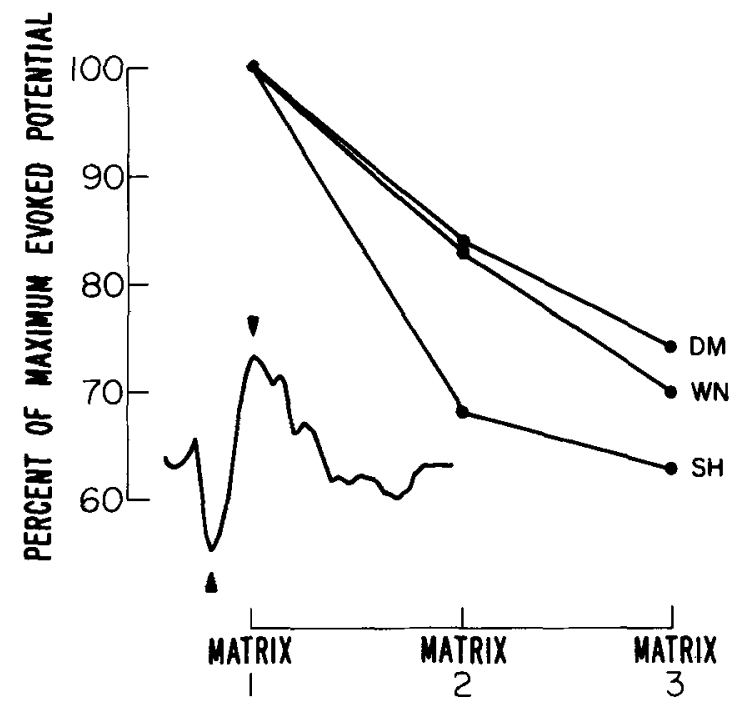

Fig. 4. The results of Experiment 2 are plotted as per cent maximum amplitude of the measured EP component for each of the three stimulus matrices shown in Fig. 3.

CLYNES, M., KOHN, M., \& LFSHITZ, K. Dynamics and spatial behavior of light evoked potentials, their modification under hypnosis, and on-line correlation in relation to rhythmic components. Ann. N.Y. Acad. Sci, 1964, 112, 468-509.

DONCHIN, E., \& LINDSLEY, D. B. Visually evoked response correlates of perceptual masking and enhancement. EEG clin. Neurophysiol., 1965, 19, 325-335.

DONCHIN, E., WICKE, J. D., \& LINDSLEY, D. B. Cortical evoked potentials and perception of paired flashes. Science, 1963, 141, 1285-1286.
HOF, M. W. VAN, VAN HOF-VAN DUIN, J., VAN DER MARK, F., \& RIETVELD, W. J. The effect of image formation and that of flashcounting on the occipito-cortical response to light flashes. Acta Physiol. Pharmacol. Neerh, 1962, 11, 485-493.

JASPER, H. H. The ten twenty electrode system of the international federation. EEG clin. Neurophysiol, 1958, 10, 371-375.

JOHN, E. R., HERRINGTON, R. N., \& SUTTON, S. Effects of visual form on the evoked response. Science, 1967, 155, 1439-1442.

JONCKHEERE, A. R. A distribution-free k-sample test against ordered alternatives. Biometrika, 1954, 41, 133-145.

KITAIMA, H. On the cerebral evoked response in man as a function of the intensity of flicker stimulation. EEG clin. Neurophysioh, 1967, 22, 325-336.

LIFSHITZ, $K$. The averaged cortical response to complex visual stimuli. Psychophysiology, 1966, 3, 55-68.

MacKAY, D. M., \& RIETVELD, W. J. Electroencephalogram potentials evoked by accelerated visual motion. Nature, 1968, 217, 677-678.

NAKAYAMA, T. Unpublished observations, Department Physiology, Nagoya (Japan) University School of Medicine, 1965.

RIETVELD, W. J., TORDOIR, W. E. M., HAGENOUW, J. R. B., LUBBERS, J. A., \& SPOOR, T. A. C. Visual evoked responses to blank and to checkerboard patterned flashes. Acta Physiol. Pharmacol. Neerl., 1967, 14, 259-285.

SHIPLEY, T., JONES, R. W., \& FRY, A. Evoked visual potentials and human color vision. Science, 1965, 150, 1162-1164.

SPEHLMAN, R. The averaged electrical responses to diffuse and to patterned light in the human. EEG clin. Neurophysiol, 1965, 19, 560-569.

WHITE, C. T., \& EASON, R. G. Evoked cortical potentials in relation to certain aspects of visual perception. Psychol Monogr., 1966, 80 (24), 1-14.

\section{NOTES}

1. The research reported in this paper was supported in part by NSF Grant GB 6093.

2. Address: Mental Health Research Institute, University of Michigan, Ann Arbor, Mich.

(Accepted for publication June 20, 1968.) 